\title{
General practice
}

\section{Effect of educational leaflets and questions on knowledge of contraception in women taking the combined contraceptive pill: randomised controlled trial}

\author{
Paul Little, Simon Griffin, Joanne Kelly, Nigel Dickson, Carolyn Sadler
}

Primary Medical
Care, Faculty of
Health Medicine
and Biological
Sciences,
Aldermoor Health
Centre,
Southampton
S016 5ST
Paul Little,
Wellcome training
fellow
Simon Griffin,
Wellcome training
fellow
Joanne Kelly,
research assistant
Nigel Dickson,
clinical teacher
Park Surgery,
Chandler's Ford,
Hampshire
SO5 2ZH
Carolyn Sadler,
family planning
trainer
Correspondence to:
Dr Little
pmc1@soton.ac.uk

BMJ 1998;316:1948-52

\begin{abstract}
Objective: To assess whether provision of educational leaflets or questions on contraception improves knowledge of contraception in women taking the combined contraceptive pill.

Design: Randomisation of women into three groups according to type of educational leaflet on contraceptive information. These groups were subdivided into two on the basis of questions on contraception asked by the doctor or practice nurse. The women were followed up by postal questionnaire 3 months later.

Setting: 15 general practices in South and West region.

Subjects: 636 women attending check up appointment for repeat prescription of the combined contraceptive pill.

Main outcome measures: Knowledge of: factors causing pill failure, subsequent action, emergency contraception, and all the rules (pill rules) that apply to the contraceptive pill.

Results: 523 women returned completed questionnaires (response rate 82\%). Knowledge of contraception with no intervention was low with only $10(12 \%)$ women knowing all the pill rules. Educational intervention had a highly significant effect on knowledge of: factors causing pill failure (likelihood ratio $\chi^{2}=22$ ); subsequent action (21); emergency contraception (24); and all the pill rules (22) $(\mathrm{P}<0.01$ in all cases). Improvement in knowledge of all the pill rules occurred with provision of the summary leaflet $(28 \%$ knew all the rules, adjusted odds ratio $4.04,95 \%$ confidence interval 1.68 to 9.75 ), the Family Planning Association's leaflet (27\%, 3.43, 1.45 to 8.09$)$, and asking questions $(26 \%, 3.03,1.30$ to 7.00). Asking questions in addition to provision of leaflets improved knowledge of contraception further for the summary leaflet $(39 \%, 6.81,2.85$ to 16.27$)$ but not for the Family Planning Association leaflet (21\%, $2.58,1.07$ to 6.18 ).

Conclusion: Women attending check ups for repeat prescriptions of the contraceptive pill should be provided with educational leaflets on contraception or asked relevant questions to help improve their knowledge of contraception. Asking questions in
\end{abstract}

addition to providing a summary leaflet is time consuming, but results in the most knowledge gained.

\section{Introduction}

Poor knowledge of the combined contraceptive pill is well documented ${ }^{1-5}$ particularly in women attending appointments in general practice, where most contraceptive pills are prescribed. ${ }^{4}$ This lack of knowledge may be a major contributing factor to pill failures and to about $20 \%$ of unwanted pregnancies..$^{146}$

Whether knowledge of contraception leads to better pill use and less unwanted pregnancies remains to be clarified. However, improving womens' knowledge of the contraceptive pill is essential if unwanted pregnancies are to be avoided; an important factor for most women taking the contraceptive pill. ${ }^{7}$

Although medical literature does advise providing women with leaflets and repeated verbal counselling on taking the contraceptive pill, ${ }^{6}{ }^{8}$ to date the effectiveness of these interventions is supported only by studies that are uncontrolled or unrandomised. ${ }^{10}$ The evidence base for such interventions-particularly during check up appointments for repeat prescriptions, which provides an ideal opportunity for giving advice-is very limited.

Our randomised study assessed the effect of two types of leaflet, and of teaching the rules of the contraceptive pill (pill rules), by asking women questions about knowledge on contraception.

\section{Subjects and methods}

\section{Study population}

Setting-We wrote to all practices listed by two health commission areas in the South and West region of England. Overall, 38 doctors and seven practice nurses from 15 general practices agreed to participate. All the practices were teaching facilities, nine were training practices and eight fundholding practices. The mean patient list size was 9183 (SD 2207).

Statistics-Sample size was calculated with EpiInfo, providing $80 \%$ power for $95 \%$ confidence, and used sample size guidelines for factorial studies. ${ }^{11}$ Based on previous studies, ${ }^{9} 507$ women (or 633 allowing for a non-response rate of $20 \%$ ) would be needed to detect an absolute difference of $10 \%$ in those knowing all the 


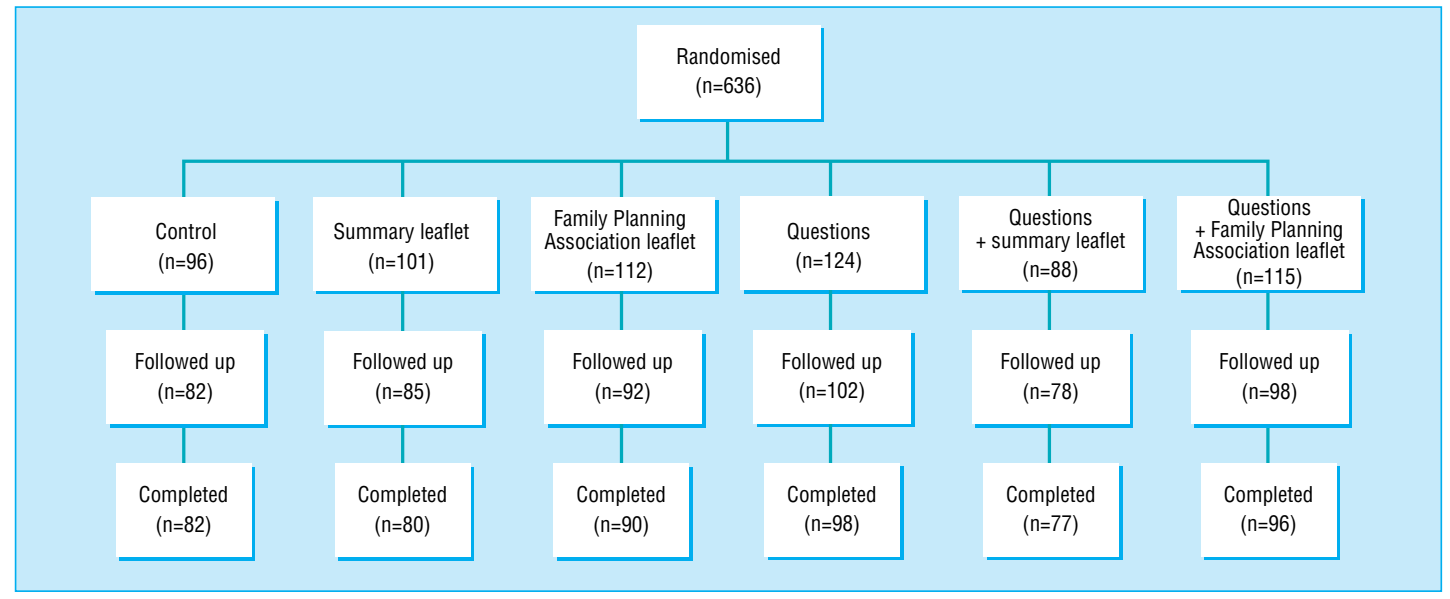

Fig 1 Number of women randomised to groups, returning questionnaire at follow up after 3 months, and providing completed questionnaires

pill rules when comparing two types of leaflet with no leaflet. This would allow detection of an $8 \%$ difference between asking and not asking questions.

Patients-From June to November 1996, a total of 636 women aged 18-45 attended a check up appointment for repeat prescription of the combined contraceptive pill at the 15 general practices participating in the study. Women were excluded if they were: aged 17 or under, owing to the sensitivity of collecting the postal outcome measures; unable to complete the questionnaire (learning disability, schizophrenia, major current manic or depressive episode, or both); or if the consultation was their first for the contraceptive pill (this created the ethical dilemma of randomising such patients to a control group where they would receive no education on the pill rules).

\section{Protocol}

Ethics-If we had provided the patients with a full discussion of the aims of the study and of the randomisation groups this would have biased the outcomes and prevented a meaningful control group. Furthermore, the control group represented normal practice, where most women are not routinely retaught all the pill rules. We therefore sought and were granted the approval of the local ethics committees to consent women to a study where they would be sent a confidential questionnaire about their contraceptive pill after 3 months.

Assignment-During consultation women were randomised to one of six groups in a $3 \times 2$ factorial design (fig 1). This was achieved by using sealed opaque envelopes that were numbered. Each envelope contained a simple management sheet for the group, containing items on what to do and boxes to tick once each item had been covered. The management sheet was determined by random numbers tables by one of us $(\mathrm{JK})$.

Interventions-The interactive questions were itemised, and the doctor or practice nurse posed each item to the patient and ticked the box as appropriate. If the women could not respond the correct answer was discussed. We aimed for an interactive rather than a simple didactic approach. The interactive questions took 2-5 minutes depending on the woman's level of knowledge. We used two kinds of leaflet. The first was a lami- nated leaflet, the size of a credit card, that contained a summary of the pill rules. The card was developed from discussions with women who took the contraceptive pill, doctors, nursing colleagues, and our advisors. The second leaflet was the latest one produced by the Family Planning Association. The leaflets were given to the women without explanation, but with a simple endorsement by the doctor or practice nurse. The management sheets and the answers to the interactive questions were all well completed.

Concealment of allocation-The consent form and intervention material were placed in stiff card in an opaque envelope. The summary leaflets were taped to the card to prevent movement, and a blank leaflet was added for groups not requiring family planning leaflets. In this way the appearance, weight, and feel of each envelope was similar; it was also impossible to guess the intervention group in pilot testing.

Outcome assessment-After 3 months the women were sent a questionnaire based on knowledge of contraception. This questionnaire had been previously validated for face, content, and construct validity. ${ }^{7}$ As 3 months is the mid point between 6 monthly appointments it should provide a good index of the average improvement in long term knowledge. The women were asked to answer all questions from memory without referral to leaflets. Second and third mailings were sent to non-responders. Data were entered by a research assistant (JK) blind to the randomisation group.

\section{Analysis}

Data were analysed using SPSs (SPSS, Chicago, IL) and Stata (StataCorp, College Station, TX) for Windows software packages. The principal intention to treat analysis of the responders' knowledge used logistic regression for a factorial study to assess the odds ratio of improving knowledge of all 12 basic pill rules (box) adjusted for the important predictors of knowledge. The effect of each variable and of interaction between the two factors was tested using the likelihood ratio $\chi^{2}$ test: terms significant at the $5 \%$ level using this test in univariate analysis were included in the logistic model by forward selection to adjust the estimates, starting with the most significant terms. Where interaction was 
Twelve basic pill rules

- Factors associated with pill failure

Severe diarrhoea

Vomiting

Missing pill by 12 hours

Starting packet late

Antibiotics

- Subsequent action after pill failure

Continue taking the pill

Extra precautions (barrier methods)

Use extra precautions during pill failure and for 7 more days (7 day rule)

Run the packets together if missed pill during the past week

Emergency contraception if had sex in pill free week and starts packet late

- Emergency contraception

Emergency pill

72 hour time limit

significant we presented the results of the individual groups defined by the two factors.

Knowledge of all the pill rules as an outcome may underestimate the ability of interventions to reduce the risk of pregnancy: any improvement in the number of rules women know is likely to improve the efficacy of pill use in the population. Thus we compared the differences in the number of basic rules that women know-using the Kruskal-Wallis test to compare groups as the data was skewed.

A secondary outcome was the number of women with knowledge (score) at follow up that was greater than the median, using logistic regression. The 32 item score included less essential aspects of knowledge of contraception-for example, factors not causing pill failure, the coil as emergency contraception, timing of pill use-and has good construct validity. ${ }^{7}$

\section{Results}

Five hundred and thirty seven women (84\%) returned their questionnaires (responders); 523 (82\%) completed all knowledge questions.

Different numbers occurred in each group owing to the variable recruitment of patients by doctors and practice nurses in the practices and the lack of block randomisation (which in retrospect would have been preferable). There was no evidence, however, of selection bias, there was thorough concealment of allocation, and similar characteristics were evident in the

Table 1 Characteristics of groups (numbers (\%) for categorical data, median (interquartile range) for continuous data)

\begin{tabular}{|c|c|c|c|c|c|c|c|}
\hline Variables & No leaflet & $\begin{array}{c}\text { Summary } \\
\text { leaflet }\end{array}$ & $\begin{array}{l}\text { Family Planning } \\
\text { Association } \\
\text { leaflet }\end{array}$ & $\begin{array}{l}\text { Pearson/ } \\
\text { Kruskal-Wallis } \chi^{2} \\
\text { ( } \mathrm{P} \text { value) }\end{array}$ & No questions & Questions & $\begin{array}{l}\text { Pearson/ } \\
\text { Kruskal-Wallis } \chi^{2} \\
\text { (P value) }\end{array}$ \\
\hline \multicolumn{8}{|l|}{ Sociodemographic: } \\
\hline Age (years) (range) & $26(22-30)$ & $26.5(22-30)$ & $27(22-31)$ & $2.9(0.24)$ & $26(21-31)$ & $26(23-31)$ & $0.6(0.42)$ \\
\hline Social class I/II & $50 / 136(37)$ & $58 / 130(45)$ & $62 / 143(43)$ & $2.0(0.37)$ & $77 / 191(40)$ & $93 / 218(43)$ & $0.2(0.63)$ \\
\hline Further education ${ }^{*}$ & $120 / 183(66)$ & 105/162 (65) & 110/187 (59) & $2.1(0.34)$ & $166 / 258(64)$ & 169/274 (62) & $0.4(0.53)$ \\
\hline Married & $114 / 182(63)$ & 104/161 (65) & 115/189 (61) & $0.5(0.77)$ & $154 / 259(60)$ & $179 / 273(66)$ & $2.1(0.15)$ \\
\hline Paid employment & 129/181 (71) & $128 / 162(79)$ & $141 / 189(75)$ & $2.7(0.26)$ & $190 / 258(74)$ & $208 / 274(76)$ & $0.4(0.54)$ \\
\hline \multicolumn{8}{|l|}{ Contraceptive details: } \\
\hline Baseline knowledge $\dagger$ & $66 / 120(55)$ & $40 / 84(48)$ & $58 / 106(55)$ & $1.3(0.52)$ & NA & $164 / 310(53)$ & NA \\
\hline Avoiding pregnancy important & 138/183 (75) & $126 / 163(77)$ & 145/190 (76) & $0.2(0.92)$ & 199/259 (77) & $210 / 277(76)$ & $0.1(0.78)$ \\
\hline Past pregnancy & $76 / 182(42)$ & $55 / 163(34)$ & $75 / 190(40)$ & $2.5(0.29)$ & $91 / 259(35)$ & $115 / 276(42)$ & $2.4(0.12)$ \\
\hline Emergency contraception in past & $66 / 183(36)$ & $35 / 162(22)$ & $53 / 190(28)$ & $8.9(0.01)$ & $74 / 258(29)$ & $80 / 277(29)$ & $0.0(0.96)$ \\
\hline No of years on contraceptive pill (range) & $7(3-10.5)$ & $7(3-14)$ & $7(4-12)$ & $2.7(0.3)$ & $7(3-12)$ & $7(4-12)$ & $0.0(0.90)$ \\
\hline
\end{tabular}

$\mathrm{NA}=$ not available.

* Six or more years of education after age 10.

†Knew one out of three sets of pill rules (pill failure, subsequent action, emergency contraception).

Table 2 Effect of intervention on knowledge of contraception (number (\%) knowing rules, and odds ratios ${ }^{\star}$ (95\% confidence intervals) of knowing rules compared with control (no intervention))

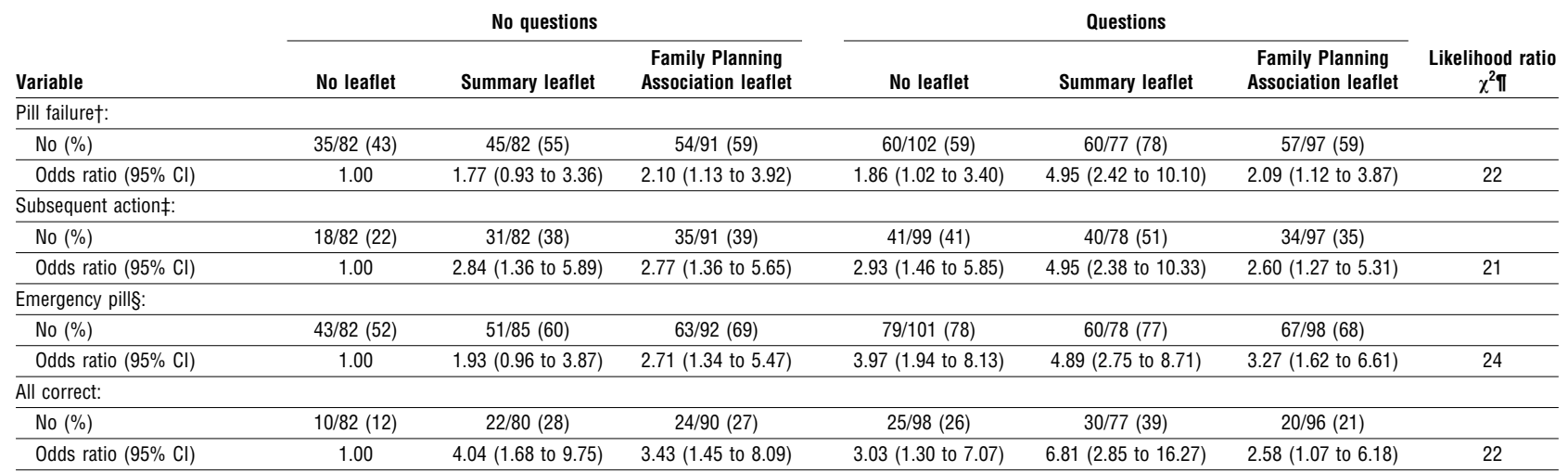

${ }^{*}$ Adjusted for past use of emergency contraception, importance of not falling pregnant, educational level, and years on contraceptive pill.

tKnowledge of all factors associated with pill failure.

$\ddagger$ Knowledge of all actions after pill failure.

§Knowledge of emergency pill and its time limit of 72 hours.

१All significant at $\mathrm{P}<0.01$. 


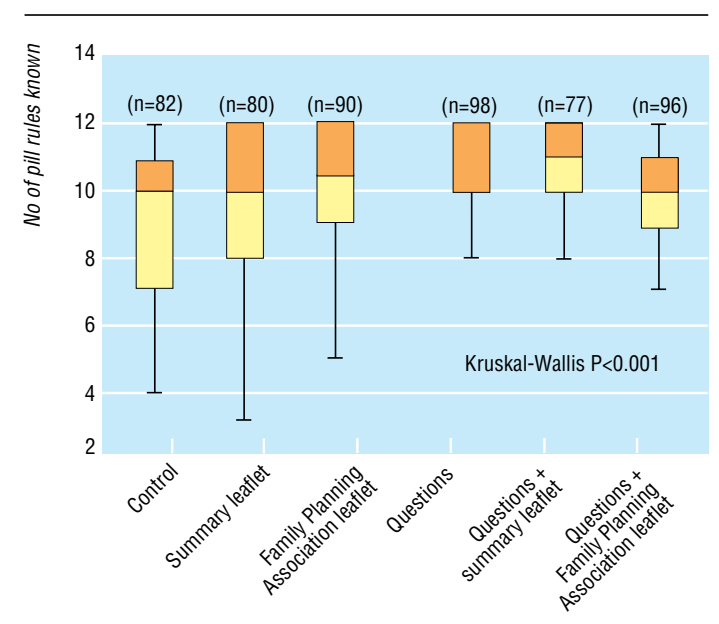

Fig 2 Boxplot of knowledge by intervention group (median, interquartile range, and range)

responders for the different levels of each factor (table 1), except women who reported use of emergency contraception in the past. This is a chance finding, but as it is a potentially important confounder the odds ratios are adjusted for this variable and for other important predictors of knowledge. The number of women $(\mathrm{n}=10)$ knowing all the pill rules with no intervention was low (12\%, table 2). For most of the women, avoiding pregnancy was important (table 1$)$.

The number of responders $(139 / 264,53 \%)$ who correctly answered the interactive questions at baseline in at least one of three areas of knowledge (pill failure, subsequent action, or emergency contraception) was not significantly different from non-responders (25/ $46,54 \%)\left(\chi^{2}=0.04, \mathrm{P}=0.8\right)$.

Selection bias-Doctors and nurses who recruited 20 or more patients were known as high recruiters. There was no significant difference in the characteristics of patients from high recruiters compared with low recruiters for those answering the interactive questions correctly for one area of pill knowledge (61/129 (47\%) and $103 / 181(57 \%)$ respectively) $\left(\chi^{2}=2.8, \mathrm{P}=0.09\right)$, importance of not getting pregnant $(177 / 224(79 \%)$ and $232 / 312(74 \%))\left(\chi^{2}=1.6, \mathrm{P}=0.21\right)$, social class I/II $(60 / 157(38 \%)$ and $110 / 252(44 \%))\left(\chi^{2}=1.2, \mathrm{P}=0.27\right)$, or education over age $15(135 / 222(61 \%)$ and 200/310 $(65 \%))\left(\chi^{2}=0.8, \mathrm{P}=0.38\right)$.

Effect of leaflets and asking interactive questions The interaction between leaflets and asking questions was significant or very close to significance for knowledge of factors causing pill failure (likelihood ratio $\chi^{2}=5.8, \mathrm{P}=0.056$ ), subsequent action (5.07, $\mathrm{P}=0.08)$, emergency contraception $(5.76, \mathrm{P}=0.056)$, and knowledge of all the pill rules $(6.23, \mathrm{P}=0.04)$. Thus the results for the six groups defined by the two factors are presented separately (table 2 ). The results suggest that all single interventions (both leaflets, and asking questions) produce a modest improvement in knowledge. Additional benefit is conferred only from asking questions with the summary leaflet.

Fig 2 (which excludes outliers) shows that intervention improves knowledge of the basic pill rules at all levels of knowledge (Kruskal-Wallis $\chi^{2}=33, \mathrm{P}<0.001$ ). Asking questions particularly helps women with poor knowledge.
Knowledge score-The odds ratio (95\% confidence intervals) of having a high knowledge score at follow up, adjusted for other predictors of knowledge of contraception, was: summary leaflet 1.73 (0.87 to 3.44); Family Planning Association leaflet 3.45 (1.75 to 6.78); interactive questions 2.14 (1.12 to 4.11 ); summary leaflet plus questions 4.41 (2.17 to 8.97); and Family Planning Association leaflet plus questions 3.31 (1.69 to $6.50)$.

\section{Discussion}

As far as we are aware, this is the first randomised trial in primary care of strategies to improve knowledge of contraception.

\section{Limitations of the study}

Exclusions-The study excluded women aged 17 or under, but included most women on the combined contraceptive pill in whom educational intervention would be considered.

Generalisability-Although only doctors and nurses from training practices participated, other practice characteristics were representative and the interventions are likely to be generalisable as the doctors and nurses were constrained by the management sheets to deliver standard interventions. Furthermore, the patient characteristics are similar to those of the largest uncontrolled study, ${ }^{10}$ and comparing patients from high and low recruiters showed no obvious selection bias. The groups had similar characteristics, with the exception of one potential confounding variable which was used to adjust the results. These results may not generalise to groups with different levels of knowledge for example, women attending family planning clinics ${ }^{4}$ : separate trials are needed in these settings.

Non-response-A response rate of $82 \%$ was achieved, and the knowledge of contraception of the responders was similar to the original randomised group.

Outcome assessment-As knowledge was self reported using a questionnaire there was nothing to stop the women from obtaining information from the inserts in their contraceptive pill packs, books, or the leaflets. To minimise this bias we asked the women not to check their answers. Even if this was the explanation for the results, this suggests intervention at least improves access to knowledge; furthermore, it does not explain the differences between groups and is unlikely to be a significant factor for most women since the final levels of knowledge were still not high. Thus despite potential limitations, the study provides reasonable estimates of the effectiveness of the interventions.

\section{Effect of interventions on knowledge}

This study shows the importance for most women of avoiding pregnancy, and confirms previous evidence that many are at risk of pregnancy because of poor knowledge of contraception. ${ }^{1-5}$ Single interventions modestly increased both the number of pill rules known and the number of women knowing all the pill rules, supporting evidence from unrandomised and uncontrolled trials. ${ }^{910}$ Leaflets are the most efficient way of increasing the number of women knowing all the pill rules as they only require seconds for a clinician to endorse. Asking questions may particularly improve understanding in those women with very poor knowl- 
Key messages

- It is very important to most women who take the contraceptive pill to avoid pregnancy

- Poor knowledge of contraception is common in women taking the contraceptive pill and associated with unwanted pregnancy

- No randomised trials have been conducted of educational interventions to improve knowledge of contraception

- Providing leaflets or asking questions both improve knowledge of contraception

- The largest effect on knowledge of contraception is from asking questions and providing a summary leaflet

edge. There is only additional benefit in asking questions when using a summary leaflet that presents information in a similar format to the questions, and not when using the more complicated Family Planning Association leaflet. Simple summary leaflets as laminated cards are not routinely available: if they are, health professionals will need to decide if the 2-5 minutes spent asking the extra questions is worth the knowledge gained.

\section{Conclusion}

Improvement in knowledge of contraception is important as most women want to avoid pregnancy, and yet very few know the basic rules for avoiding pregnancy. Health professionals should provide leaflets or ask questions on knowledge of contraception, or both, at consultations for repeat prescriptions of the contraceptive pill, as education seems to improve knowledge of contraception even after one consultation.

We thank the following doctors and practice nurses for their help in recruitment, constructive comments, and enthusiasm: Drs Stephens, Gibson, Barnsley, Bond, Moore, Glaysher, Stanger, Higgins, O'Connor, Podkolinski, Dickson, Terry, Thompson, Wood, Munro, Stobbs, Darch, Boyd, Godfrey, Lupton, Chaplin-Rodgers, Richenbach, Bacon, Fowler, Mooney, Mansell, Snell, McCallum, Meakins, Baber, Ord-Hume, ReesJones, Das, and LeBesque, and sisters Redman, Barr, Davies, McCrea, Roe, Bunyan, and Winter. We thank Dr Christine Glew, Professor John Guillebaud, Dr Elaine Cooper, and Dr Sarah
Randall, the patients and staff at Aldermoor Health Centre, the general practitioners, and the family planning doctors who gave their time during development of the questionnaire. We thank the Family Planning Association for the use of their leaflets.

Contributors: PL had the original idea for the present study, led the grant application, supervised the development and conduct of the study, performed the main analysis, and wrote the main drafts of the paper; he will act as guarantor for the paper. SG contributed to writing the grant application, supervised the development and conduct of the study, jointly performed the main analysis, and contributed to the writing of the paper. JK managed all phases of the study, entered and checked the data, contributed to the development of the interventions, the questionnaire, the analysis, and writing the paper. ND contributed to the grant application, development and supervision of the study, development of the interventions and the questionnaire, and writing the paper. CS contributed to the development and supervision of the study, and the development of the interventions, the questionnaire, the analysis, and writing the paper. Dr Christine Glew was responsible for the day to day management of the development phase of the study and contributed to the development and validation of the questionnaire. Professor Guillebaud, Dr Sarah Randall, and Dr Elaine Cooper contributed to the development of the questionnaire and the interventions.

Funding: This work was supported by Wessex NHS regional research and development funds. PL and SG are supported by the Wellcome Trust.

Conflict of interest: None.

1 Duncan G, Harper C, Ashwell E, Mant D, Buchan H, Jones L. Termination of pregnancy: lessons for prevention. Br J Fam Plann 1990;15:112-7.

2 Finlay IG, Scott MGB. Pattern of contraceptive pill taking in an inner city practice. BMJ 1986;293:601-2.

3 Brook SJ, Smith C. Do combined oral contraceptive pill users know how to take their pill properly? BrJ Fam Plann 1991;17:18-20.

4 Bromham DR, Cartmill RSV. Knowledge and use of secondary contraception among patients requesting termination of pregnancy. BMJ 1993;306:556-7.

5 Wilson S, Taylor R. Women's knowledge about contraception. Br J Fam Plann 1992;18:3-5.

6 International Working Group on enhancing patient compliance and oral contraceptive efficacy. A consensus statement: enhancing patient compliance and oral contraceptive efficacy. Br J Fam Plann 1993;18:126-9.

7 Little PS, Glew C, Kelly J, Griffin S, Dickson N, Sadler C. Contraceptive knowledge: development of a valid measure and survey of pill users. $\mathrm{Br} J$ Fam Plann (in press).

8 Anonymous. Hormonal contraception. Medicines Resource Centre Bulletin 1996;7:33-36.

9 Metson D, Kassianos G, Moriarty J, Norman D. Effect of information leaflets on long term recall-useful or useless? Br J Fam Plann 1992;17:21-3.

10 Smith L, Whitfield M. Women's knowledge of taking the oral contraceptive pill correctly and of emergency contraception: effect of providing information leaflets in general practice. Br J Gen Pract 1995;45:409-15.

11 Day SJ, Graham DF. Sample size and power for comparing two or more treatment groups in clinical trials. BMJ 1989;299:663-5.

(Accepted 6 April 1998)

\section{One hundred years ago Italian duels}

The sad death of Signor Cavalotti in a duel will, it is to be hoped, do something to create a healthier state of feeling among his countrymen as to these foolish encounters, which are, as the Duke of Wellington said, a relic of barbarism. The wound by which the Italian statesman lost his life was a remarkable one, his adversary's sword entered his mouth, penetrated the tongue, and severed the jugular vein, causing almost immediate death. It is probable that in the impetuosity of his attack Signor Cavalotti spitted himself on the point of his adversary's weapon, as did General Boulanger though with a less serious result, in his famous meeting with $\mathrm{M}$ Floquet. There is a pretty general impression that Italian duels are of a peculiarly bloodthirsty character. This is not the case, though it is certain that they are not the stage combats by which honour is so easily satisfied in
France. Duels are especially frequent in Italy amongst journalists, officers of the army, and members of Parliament. They are usually of no importance, serious wounds seldom occur, and death is extremely rare. They can be divided into two categories: First, a primo sangue, in which the adversaries fight till one of them is wounded or scratched; and secondly, a ultimo sangue, when the combat is continued till one of the adversaries is completely disabled. One or two doctors are always in attendance. The weapons used in Italy are the cavalry sabre and the fencing sword, and in rare eases the revolver. Duels a primo sangue are the most frequent; they generally end in a good supper. Cases like that which ended so tragically this week are happily rare, and are mostly the result of accident. (BMJ 1898;i:716) 


\title{
Primary care: core values \\ Contracting for general practice: another turn of the wheel of history
}

\author{
Brian M Goss
}

British general practitioners often assert their pride at being "independent contractors," without remembering the origin of the term. Dr Ransome, pictured on his rounds as visiting physician to the local cottage hospital (box), was one of my predecessors in practice, and his extract from Kelly's 1908 directory of trade and professional people reminds us how most of our medical forebears earned their living. ${ }^{1}$ Others of my 19th century medical ancestors are entered in such directories as Surgeon to Waveney Valley Branch of Great Eastern Railway (Dr Adams, 1875²), Surgeon to the Dispensary for the Poor (Dr Garneys, 1828 ${ }^{3}$ ), and Surgeon to the Rational Sick and Burial Association (Dr Johnstone, $1890^{4}$ ).

This collection of contracts included occupational and public health services, treatment and certification of subscribers to friendly societies, care of inpatients at cottage hospitals, and a very basic service to the indigent poor (whether inside workhouses or on "outdoor relief," as the forerunner of social security payment was called).

Although these arrangements initially seem to be relics of a bygone age, the modern general practitioner immunises children and adults, sees patients at the surgery or in the home, visits residential homes, and has hospital practitioner contracts at a community hospital or in a district hospital specialist department-he or she has a spectrum of work that bears a remarkable resemblance to that of Dr Ransome and his Victorian colleagues.

As well as these contracts, these doctors would have undertaken private consulting practice. John Scott, a well to do local diarist, records that he consulted $\mathrm{Dr}$ Garneys about his feeble sister Charlotte ${ }^{3}$ and, on behalf of concerned local worthies, about the 1849 outbreak of cholera in the town ${ }^{5}$. On New Year's Eve 1828 Dr Garneys was even called on to "dissect" Scott's gardener, James Baker, who died of "Billious Fever and Metastasis ... leading to congestion of the brain." ${ }^{3}$

\section{General practice in the NHS}

The NHS arose from the atmosphere of social cohesion and unity of national purpose that developed during the second world war. It is neatly expressed in the famous "assumption B" of the Beveridge report, which gave rise to the NHS:

That a comprehensive national health service will ensure that for every citizen there is available whatever medical treatment he requires, in whatever form he requires it, domiciliary or institutional, general, specialist, or consultant, and will ensure also the provision of dental, ophthalmic, and surgical appliances, nursing and midwifery, and rehabilitation after accidents. ${ }^{6}$

After the foundation of the NHS in 1948 general practitioners became used to receiving ever higher proportions of their gross income from NHS

\section{Summary points}

General practitioners have held multiple contracts since the last century

After the NHS was established general practitioners became dependent on it for income, to the exclusion of other income streams

Recently their income in the NHS has fallen below that of other professional groups in the private sector

Rising expectations, coupled with increasing public resistance to taxation, mean that to maintain income general practitioners may have to develop a wider portfolio of contracts, including private consulting practice

For personal care from general practitioners to survive, doctors may have to adapt to economic and social realities that may not be to their taste

sources. Many have now spent their entire working life within the NHS:

I qualified [in 1952] and will retire from full-time clinical practice in 1988; the NHS allowed me to do my own work and refer my patients to the whole range of specialist services during an entire working lifetime, without ever having to collect a fee. Several generations of British

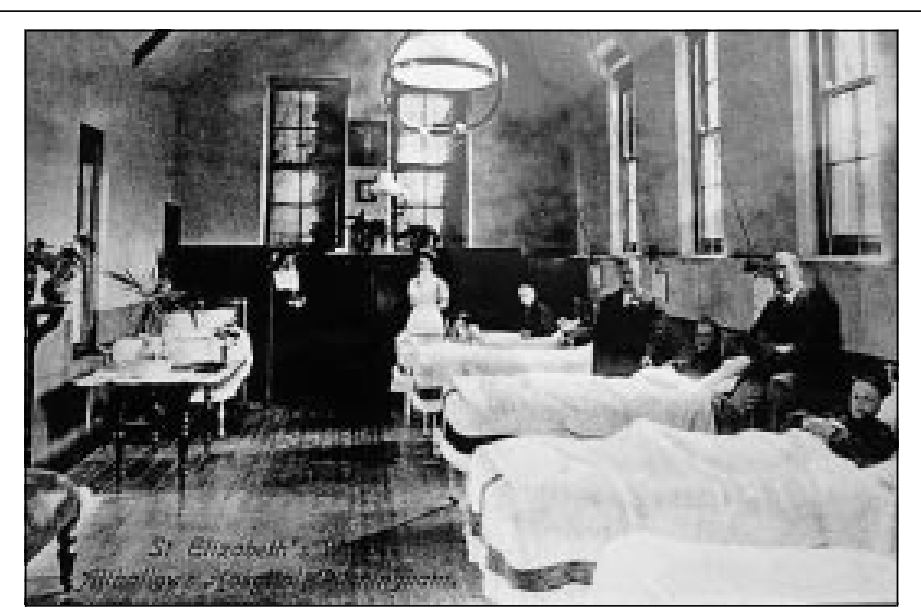

RANSOME, Gilbert Holland. LRCP Lond, MRCS Eng. Physician \& Surgeon. Medical officer and public vaccinator to Bungay District Council. Medical officer to Wangford Union and 4th District. Medical officer to Loddon and Clavering Union and 2nd District. Medical officer to Depwade Union. (Kelly's Directory of Suffolk, 1908) 
doctors have followed, with essentially the same historically novel experience. ${ }^{7}$

\section{End of the NHS era}

The social consent needed to fully fund a comprehensive NHS, free at the point of delivery, can, I fear, no longer be relied on-a reality which general practitioners may be the last to recognise, despite their falling income against comparator professions since 1980.

Neither of the two major political parties in Britain has committed itself to raising taxation in order to increase spending on the NHS and other public services. The public has shown increasing tolerance of erosions at important margins of the NHS over the past three decades (under both right wing and left wing governments), including the progressive partial privatisation of care of the elderly, optical services, and dental services; the private finance initiative; and enormous leaps in prescription charges, all tolerated without political damage. Public consent for privatisation is not expressed through lack of commitment to the NHS, which is highly valued, but through a reluctance to accept the increased taxation that is necessary to deliver Beveridge's "assumption B."

The public is also willing to pay for supplementary health services and products, including burgeoning publications and telephone advice lines on health, private general practice on demand in railway stations and other locations, a steadily increasing market in over the counter medicines, and private elective surgery. On the other hand, compared with other developed countries, the United Kingdom still has a strikingly low proportion of private health spending.

A mixed economy between NHS and private work is accepted by many dentists and consultants as part of

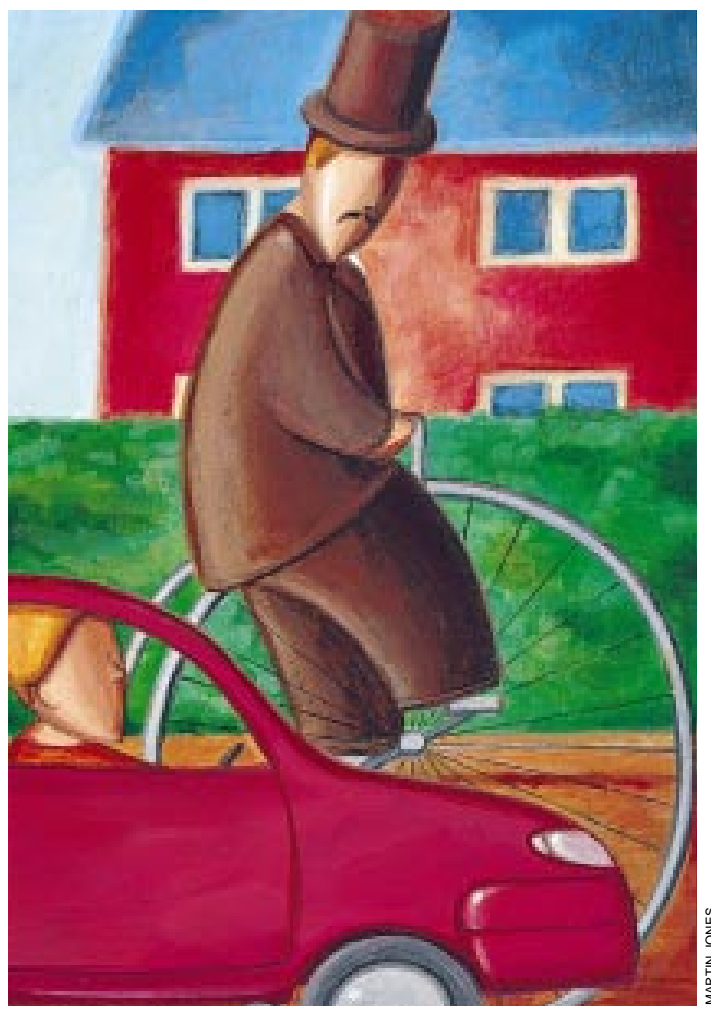

their traditional pattern of work. This does not sit so easily with general practitioners, however, who are inhibited from mixing NHS and private work for the same patient not only by philosophical inclination but by their terms of service.

Despite this, general practitioners in the closing years of the century may have to bring a higher and more flexible proportion of private funding into general practice, given that the opportunities and political will to invest in the NHS from public sources seems increasingly limited.

\section{Recognising GPs' limits}

General practitioners, on the whole, remain fiercely committed to a comprehensive NHS. Yet recent developments in general practice signify their willingness to recognise the personal and professional limits of doctors' ability to meet the quantity and nature of demand, in a way that would have been unthinkable a decade ago.

After a crisis in out of hours primary care in $1995,{ }^{8}$ doctors, patients, and the government alike recognised that a service based entirely on home visits could not satisfy rising demand within existing financial constraints. Consequently, and with modest additional funding from the government, general practitioners began to offer out of hours care at primary care premises and to work together in cooperatives covering larger areas and larger populations.

At around the same time general practitioners demanded set limits on the scope of their practice. ${ }^{9}$ This arose mainly from the considerable shift in work from the secondary to the primary care sector, without shifted funding, following the internal market reforms in the NHS of 1990.

The publication of a clear definition of core general practice in 1996 allowed family doctors to draw a line in the sand, showing the myriad small tasks farmed out from hospitals, and the care of patients sent to nursing homes who would, formerly, have occupied places in long stay hospitals.

General practitioners have responded to the definition of core services in various ways. Some have been keen to take additional training to contract for new non-core tasks or care for more complex groups of patients under supplementary contracts. Others have insisted that they do not wish to undertake the non-core work, even under contract. The 1997 Primary Care $\mathrm{Act}^{10}$ opened up further contractual possibilities for general practitioners. General practice can now be provided under a contract made by health authorities with a trust or group of practitioners instead of having to be provided under the traditional and highly regulated environment of part 2 of the 1977 NHS Act. In the new style of practice, patients will register with the trust rather than with an individual doctor, and responsibility will be held by the organisation. The employed doctors will have contractual responsibilities to their employers. This model has been further encouraged by the labour government's white paper The New NHS, which encourages doctors to move towards primary care trust status. 


\section{The future of contracts}

The future general practitioner will probably have a wide network of contracts. As resources fail to expand to meet demand the NHS contract for general practice may be increasingly focused on the poorest and most deprived patients, leaving the better off to make private provision from the proceeds of a low tax economy.

General practitioners with wide ranging skills and interests may, however, contract to care for specialised groups in nursing and residential homes, to provide surgical services and procedures within their practices, to perform occupational health examinations and give advice, to provide services to a corporate provider in the primary healthcare business, and, eventually, to contract individually with private patients.

Whatever general practitioners do, they always need to remember the nature of their core business. The following words from an early draft of the BMA's statement on core services encapsulate what general practitioners are best at and what they see as their central expertise, regardless of whether the funding comes from public, private or mixed sources.

The irreducible essence of general practice is the care of people who are or believe themselves to be ill. Sensing unease within themselves which is not resolved using their own perceptions or the resources of those around them, people seek a consultation to secure an understanding of what is happening to them, what it means and what might be done with what effect. This aspect of human behaviour transcends history, geography and culture and will survive the ephemeral health policies of transient governments. Providing a response to these concerns is what most GPs feel they are best at and are happiest doing. By identifying the heart of our craft as the response to this timeless human need, we at a stroke restate our raison d'être and define our sovereign professional territory at a time of doubt and demoralisation. ${ }^{11}$

\section{Adapt or perish}

Sadly, the public's aversion to taxation means that general practitioners are still prone to the sort of pressure and exploitation in the public service that Punch magazine satirised a century and a half ago (box), and which survives today in the form of the Doctors and Dentists Review Body. The survival of personal medicine requires, as it always has done, imaginative adaptation by doctors to the economic and social reali-

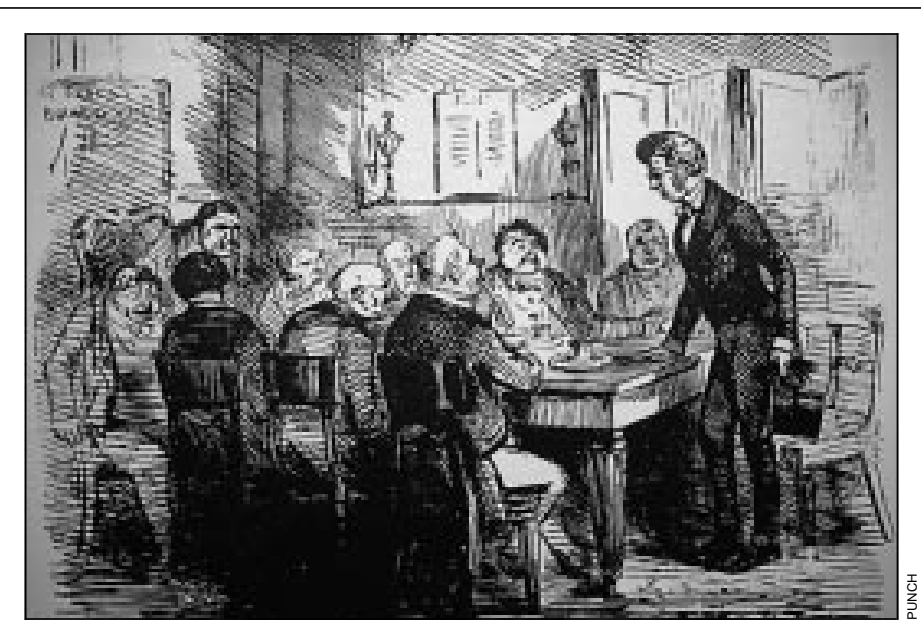

Chairman: "Well, young man. So you wish to be engaged as parish doctor?" Doctor: "Yes, gentlemen, I am desirous-"

Chairman: "Ah! Exactly. Well, it's understood that your wages-salary I should say-is to be twenty pounds per annum; and you find your own tea and sugar medicines I mean-and, in fact, make yourself generally useful. If you do your duty, and conduct yourself properly, why-ah-you-ah-" (Punch: "Will probably be bowled out of your situation by some humbug who will fill it for less money.")

ties that surround the timeless human need for access to healers.

Funding: None.

Conflict of interest: None.

1 Kelly's Directory of Suffolk, 1908

2 Kelly's Directory of Suffolk, 1875

3 Mann E, ed. An Englishman at home and abroad 1792-1828: extracts from the diaries of John Barber Scott of Bungay. Bungay: Morrow \& Co, 1988:217. Rayner's Bungay Almanac, 1890.

5 Mann E, Cane H, eds. An Englishman at home and abroad 1829-1862: extracts from the diaries of John Barber Scott of Bungay. Bungay: Morrow \& Co, 1996:160.

6 Beveridge, WH. Social insurance and allied services. London: HMSO, 1940.

7 Hart JT. A new kind of doctor. London: Merlin, 1988.

8 Beecham L. Decision on out of hours package endorsed. BMJ 1995;311:1170.

9 General Medical Services Committee. Core services: taking the initiative. London: GMSC, 1996.

10 National Health Service (Primary Care) Act. London: Stationery Office, 1997

11 General Medical Services Committee. Annual report, 1995. GMSC, 1995. (Appendix II: Core general medical services and the classification of general practitioner activity.)

\section{A lesson learnt}

\section{Non-specific but effective}

I do not even remember her name, only her diagnosis: angina pectoris. She was an elderly lady who reminded me of my grandmother. At the time I was a medical student and my task was to wire patients up for electrocardiography. This, I thought, was both exciting and important.

My patient was extremely nice; she even addressed me as "doctor," and I remember how this made me smile. The procedure went smoothly and I soon managed to get a neat recording, disconnected the patient from the leads, and asked her to dress. When she had done so she gave me a tip-the only tip I ever received and the first money I earned in medicine-and said: "Thank you so much doctor. I feel much better. My chest pain has completely vanished."
I did not know how to answer and it took me a while to collect my thoughts. There had been no treatment, so why was there a therapeutic effect? Did she just improve temporarily by chance? Perhaps she was only trying to be kind and had not really improved at all? Was it due to a non-specific effect of my diagnostic intervention? If so, what brought it about? Her expectation? My empathy? The high tech atmosphere of electrocardiography?

These questions remain unanswered to the present day. The incident, however, started me thinking. Perhaps non-specific therapeutic effects are more important than my teachers had told me.

Edzard Ernst, professor of complementary medicine, Exeter 